\title{
Making the right choices \\ Pay-per-view use data and selection decisions
}

$\mathbf{T}$ he library at Lafayette College is one of a number of institutions that have recently turned to pay-per-view access to replace some journal subscriptions. ${ }^{1}$ When we began to implement pay-per-view, we looked forward not only to increasing users' access to journals and reducing costs, but also to getting a better picture of what our faculty and students would use if they had ready access to all of a publisher's titles. As we examined use statistics after the first year of our pay-per-view experience, we weren't surprised to see that the number of titles used expanded far beyond those to which we had been subscribing. We had hoped, however, that our previously subscribed titles would be among those with the highest use and that few of these titles, if any, would receive no use. This proved not to be the case.

\section{Pay-per-view implementation}

Our foray into pay-per-view began with Elsevier's ArticleChoice program. At the end of 2008, we canceled all of our Elsevier subscriptions and provided faculty and students with access to almost all of Elsevier's titles via ArticleChoice. Information about each title available was included in the library catalog and coverage information was added to our OpenURL resolver's knowledgebase.

To control the costs of the program, we adopted a policy where only faculty could download articles unmediated. Students accessed articles via an online interface that forwarded e-mail requests to a librarian. The librarian would either e-mail the requested article to the student (within two hours during regular reference hours) or, if the article was available in the library's print collection, direct the student to the paper copy. This modest requesting "hurdle" increased the probability that a student genuinely wanted the article and mitigated casual downloading that could greatly increase the cost of the program.

\section{Periodical selection and review process}

Before we made this switch to pay-per-view access, librarians felt fairly confident that we were subscribing to Elsevier titles that were important to our faculty and students, although we knew that they wanted access to even more titles than the 98 we had selected. Every year faculty from each department reviewed lists relating to their disciplines and were the primary drivers of any changes. While some departments were more vigilant than others, we knew that departments in the natural sciences, which by far had the majority of the Elsevier subscriptions, took the task seriously, because if they wanted to add titles—which they usually did-they had to cut titles of equal cost. Since 2000, we had twice gone through a series of periodical cuts that forced departments in the natural sciences to winnow their collections. Librarians also annually reviewed interlibrary loan data to see if any titles were requested so frequently that they warranted subscriptions.

Michael Hanson is acquisitions and serials librarian, e-mail: hansonm@lafayette.edu, and Terese Heidenwolf is associate director for research and instructional services, e-mail: heidenwt@lafayette.edu, at Lafayette College

๑ 2010 Michael Hanson and Terese Heidenwolf 
So by the time that we canceled our Elsevier subscriptions in December 2008, we thought that those subscriptions represented a core list of titles that were of high importance to our faculty in their roles as teachers and scholars and by extension of importance to their students. We were surprised, then, when we examined our use data for Elsevier titles after a year of pay-per-view and found that only three of the ten most used titles had been on our list of subscribed titles. Even given that there were two additional titles in the top ten that we had repeatedly considered subscribing to but rejected because of the high price, we were surprised that our list of selected titles was not a better predictor of those that were most used when we turned to pay-per-view.

\section{Eye-opening data}

Others have compared collection developers' selection choices with patron-driven selection, generally in the context of exploring the cost/benefits of "big deal" packages. For example, in 2001 David Kohl found that selected periodical titles at Ohio universities and colleges did not match downloaded titles from OhioLINK databases, concluding that the demand for access to journal literature is best satisfied by broad access to a large number of titles. ${ }^{2}$ In 2007, Narda Tafuri found that SpringerLink article requests at the University of Scranton did not reflect previously selected titles. ${ }^{3}$ Tim Bucknall observed that only six of the top ten most used Wiley journals at University of North Carolina-Greensboro, and 12 of the top 20, were subscribed titles. ${ }^{4}$

Given these findings, perhaps we shouldn't have been surprised that our selected titles didn't better match those with high use. We had thought, however, that our selection process and data captured some nuances that might yield different results. Our small size and close relationship with faculty afforded us the opportunity to let our primary users determine our subscriptions. And while the "big deal" studies included data where even the most casual clicks on full text were counted as use, our data likely recorded more instances where a journal was purposefully sought, since faculty were reminded at the point of purchase that the library was being charged per article and students' access was mediated. These hurdles, while not high and we hope not off-putting, allowed us to capture use data of a different quality than that produced from package deals.

In 2008, Lafayette subscribed to 77 Elsevier periodicals and 21 standing orders, totaling 98 titles. With ArticleChoice, we have access to 2,848 titles. In the calendar year 2009, 2,085 articles from 612 titles were used. (We included in this data instances where a journal was sought, but the patron was referred to the paper copy.) Use of the 98 previously selected titles breaks down this way:

- 3 of top 10 most used titles had been subscribed to in 2008;

- 8 of top 25 most used titles had been subscribed to in 2008;

- 12 of top 50 most used titles had been subscribed to in 2008;

- 32 of 98 , or 33 percent, were not used.

Twenty-seven titles were downloaded more than ten times and accounted for nearly 30 percent of all use; we considered these high-use. Of these, eight had been on our subscription list, three we had considered subscribing to, and four were at least familiar because they were requested fairly frequently via interlibrary loan. But 12 of these high- use titles weren't even on our radar screen. We had no faculty requests to purchase them in recent years, and none of them were requested more than ten times via interlibrary loan in 2008. (In fact, most had fewer than five requests.)

\section{Were some departments better selectors?}

Not all of our departments put equal effort into scrutinizing their subscriptions. Since a large part of our confidence in selection decisions was based upon faculty's involvement in the process, we examined data more closely from two departments that were par- 
ticularly vigilant to ascertain if their selected titles more accurately matched actual use.

The biology department subscribed to 22 Elsevier periodicals. Three of these were used more than ten times in a year, but there were a number of other biology titles with high use that hadn't been on our subscription list. Seven of the 22 titles were not used at all.

The geology department subscribed to nine Elsevier periodicals. None of the titles were used more than ten times, and one was not used at all. The geology title with the highest number of downloads had been cancelled at the department's request in 2006.

It seems that even our most conscientious departments, who carefully monitored their titles, had trouble identifying some important titles, either for new selection or retention.

\section{Conclusion}

We expect that when we have a year's worth of use data from other publishers' packages they will similarly reveal that our selections were not as on-target as we had presumed. These results raise questions about the adequacy of our periodical selection and review methods. Is a careful annual review with heavy faculty input insufficient to identify the titles of greatest worth for our collection?

Perhaps this method doesn't allow us to be responsive enough to changes that affect journal use-changes brought about by new access tools, by increased interest in interdisciplinary studies, or by subtle shifts in journal content profiles. Is demand being constantly reshaped by so many forces that predicting high-use titles is increasingly difficult? Is demand becoming so diffuse and malleable that the number of titles that can be deemed consistently high use is shrinking?

As we try to answer these questions, we'll continue to keep a close eye on use data and will be particularly curious to see how much consistency there is in high-use titles from one year to the next. If we have to return to a subscription model for titles from Elsevier and other publishers, we hope we'll be able to make our new subscription selections from a position of strength, using data on past use to guide our decisions.

\section{Notes}

1. For a recent review of some institutions that have implemented pay-per-view access, see Patrick L. Carr, "Acquiring Articles through Unmediated User-Initiated Pay-PerView Transactions: An Assessment of Current Practices," Serials Review 35 (2009): 272-277.

2. David F. Kohl, "To Select or Not Select: Taking Off the Blinders in Collection Development" Collection Management 26 , no. 2 (2001): 6 .

3. Narda Tafuri, "Smoking out the Big Deal: Getting What You Want without Getting Stung" Serials Librarian 56 (2009): 117.

4. Tim Bucknall, "Are Consortium 'Big Deals' Cost Effective? A Comparison and Analysis of E-Journal Access Mechanism -Workshop Report" Serials Librarian 55 (2008): 473. $n$

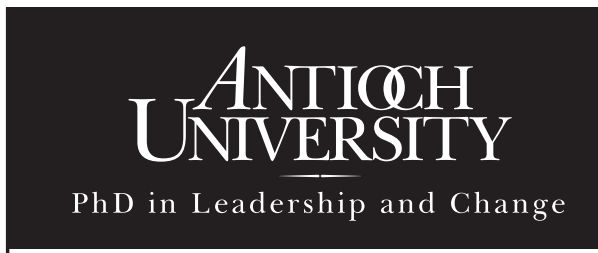

A low-residency program that combines faculty-mentored, individualized learning with a challenging interdisciplinary core curriculum.

This distinctive program is for professionals seeking a degree that offers:

- Quarterly residencies

- Learner-centered focus

- Integration of theory and practice

- Flexibility of pace to completion

- Academic Mentoring

\section{www.phd.antioch.edu}

